\title{
HUMAN RIGHTS AND DISABILITY DEBATE WrOCŁAW, 14 SEPTEMBER 2019
}

\begin{abstract}
The Human Rights and Disability Debate was organized within the $17^{\text {th }}$ Polish Sociological Congress that took place in Wrocław in September 2019. It was the first time that the Sociology of Disability Section organized and chaired a series of sessions dedicated to the disability. Sessions were not only sociological, but also tackled disability from different perspectives, both practical and academic (participants were an interdisciplinary group of academics, researchers and practitioners).
\end{abstract}

Keywords: Human Rights, Disability, Sociology of Disability

Creating the English-language version of the journal "Zoon Politikon" is financed under contract No. 724/P-DUN/2018 from the funds allocated by the Minister of Science and Higher Education for dissemination of science. 
The Human Rights and Disability Debate was organized within the $17^{\text {th }}$ Polish Sociological Congress that took place in Wrocław in September 2019. It is worth mentioning that the 2019 Congress was the first time that the Sociology of Disability Section organized and chaired a series of sessions dedicated to the disability. Sessions were not only sociological, but also tackled disability from different perspectives, both practical and academic.

The idea of this particular session was not to present and listen but to discuss, confront and to do so in an interdisciplinary group of academics, researchers and practitioners. I believe that we (Elżbieta Zakrzewska-Manterys and me - session's chairs) did not expect the debate to engage the audience so much and to inspire a very dynamic discussion both between the panelists and the listeners who became its active participants. It was definitely a positive surprise.

The panelists presented various approaches to the term "disability". We discussed the United Nations Convention on the Rights of Persons with Disabilities (UNCRPD), which was ratified by Poland in 2012, and its consequences. We focused on intersectional character of disability, especially when it comes to women with disabilities or persons with disabilities from minorities. We also discussed the minority-majority relations and cultural approaches to disability that try to perceive persons with disabilities as minority. We tackled the issues of norms (normalcy) and professionals that play a significant role in the lives of persons with disabilities and their relatives.

The added value of the debate was its interdisciplinary profile which reflected the interdisciplinary nature of Disability Studies.

We hope that the transcript of our debate will serve as a source of inspiration for other scholars and practitioners. It also captures a particular stage of the Polish disability studies' development.

The debate was transcribed by Elżbieta Zakrzewska-Manterys ${ }^{1}$ and Krzysztof Pezdek.

All participants are listed below the transcript.

Marta Sałkowska

\footnotetext{
' Professor Elżbieta Zakrzewska-Manterys, University of Warsaw, Poland, mail: ezakrzewska@isns.uw.edu.pl, ORCID: https://orcid.org/ 0000-0003-3727-4411.

2 Marta Sałkowska, Ph.D., Collegium Civitas, Warsaw, Poland, mail: marta.salkowska@civitas.edu.pl, ORCID: https://orcid.org/0000-0000-90000-0000.
} 
Elżbieta Zakrzewska-Manterys

Our debate is special, for both substantive and methodological reasons. Substantive because, as a section of Sociology of Disability ${ }^{3}$, we are participating in the Sociological Congress for the very first time. This will initiate the discussion on disability as a separate topic of sociological research. The methodological reason lies in our innovativeness, because we have proposed a different mode of the debate to the organizers which relies on contributions, rather than scheduled speeches. We expect that our meeting will be dynamic and interactive, resulting in the emergence of new ideas. We propose the form of a panel discussion, that is, a series of speeches on selected topics and following discussion from other participants. We want to highlight the civic, inclusive aspects of the presence of people with disabilities in the public space.

There are also people with hearing loss among us, who will present their own perspectives on participation in the social world. I hope this will provide a new quality in our discussion. There is a sign language interpreter here with us.

Magdalena Kocejko

I would like to discuss the Convention on the Rights of Persons with Disabilities and outline the ongoing dispute within the framework of the Convention concerning the issue of the disability paradigm and its practical implications in terms of how individual countries should implement the provisions of the Convention.

From my own practice, but also from various scientific considerations, I have a feeling that we are stuck thinking that the Convention introduces a social understanding of disability. Of course, this understanding is to some extent correct as a particular paradigm of

3 The Sociology of Disability is a section of The Polish Sociological Association, established in 2018. 
policy planning, applicable to both disability policies and public policies overall. The human rights are in the background, but the link between the two approaches is elusive at times.

In my speech, I would like to present two theses.

Firstly, the social model as a basis for disability policy and as a target way of thinking about disability is definitely insufficient. This is not something we should be aiming for. Here in Wroclaw, in the span of three days, substantial criticism of the social model was presented, but a great deal of hope that this social model would be something to introduce, especially from the level of policy planning and implementation, was expressed. I think this is a matter to discuss. It is not like we all have to pursue it. The core criticism of the social model is that it somewhat overlooks what we call "impairment" or the medical model of disability, and omits the diversity of the whole group of people with disabilities and how varied an experience a disability can be. This has a very practical impact on how it is perceived from the level of public policy. With this assumption, there is a lot that evades us. Even if the dream of all policies conforming to the social model is fulfilled, they will only focus on a few rights and many other will be omitted. The social model focuses on the elimination of barriers and even if we understand them very broadly, these are only: architectural, attitudinal and communication barriers.

The second thing that the social model focuses on is the pursuit of activity. It encompasses the right to be active, as a professional and as a citizen, but it seems to me that the latter is less emphasized. Still, it is evident that the able-bodied majority defines disability and determines who receives certain rights. Apart from the fact that the social model excluded a large group of people with disabilities because it focused, especially in the Polish version, on those with sensory and physical disabilities, mainly on men because of its non-intersectional nature - it also focused on productivity. This is paradoxical, because very few people with disabilities find employment in Poland. 
The second thesis, which elaborates on the discussion on the Convention, proposes that we should discuss these aspects in Poland, as an academic community, as a movement for people with disabilities and their allies, and in advocacy activities - that the target model should be based human rights, in a version, which Theresia Degener, one of the creators of the Convention and a representative of the UN Committee on the Rights of Persons with Disabilities, calls "inclusive equality". How does this differ from the social model as we understand it?

Degener said that there is a social model in the Convention, there is no denying it, but it is not sufficient. We need progress. The move forward aims towards full empowerment, that is, the assumption that the rights of all persons are inalienable and that all rights are equal and cannot be opposed in any way. We cannot say that yes, people have a right to benefits, but labor should come first. All rights are equivalent.

Degener also says that the whole issue of identity in relation to disability is important. I think that in a pure social model, within the framework of the disability movement and advocacy activities, the fact that disabilities are varied and it is difficult to talk about all people with disabilities simultaneously was eluded. For example, the identity associated with deafblindness cannot easily be reduced to "eliminating barriers".

In a legal-humanist approach, all rights are inalienable. Dignity, subjectivity and autonomy are permanent. What is not left out is the whole fact that the rights of people with disabilities should be implemented through, for example, a very good health policy, very good social protection and by ensuring the possibility of an independent existence. I would like to emphasize this, as it demonstrates the difference - it is clear how these rights are intertwined. We have the right to be free, to live outside theinstitution, but we also have the right to need a state which provides sufficient social services in order to 
facilitate living outside the institution. "Inclusive equality" - this is the step forward. As a society, we do not divide ourselves into persons with and without disabilities. Identity is complex, the whole phenomenon is intersectional, and we should also consider it in public policy.

Krzysztof Pezdek

The previous speaker presented a beautiful world of ideas. There is no division between the able-bodied and the disabled, we live in the same society. This is the world of ideas, namely, there is a theoretical world which, unfortunately, does not exist in our changing reality. In a changing reality we share, we have norms that standardize our lives.

Therefore, we have a model of social disability which is a kind of superidea, i.e. it basically does not exist outside of the theoretical sphere. This model exists in the minds of intellectuals and scientists, but does not exist in everyday life.

As Magda Kocejko said, there are many people who are somehow deprived of their identity, personality and subjectivity by that model. That is true, because every model based on a norm deprives us of something, so we can generally say that the norm is depersonalizing. The norm therefore has nothing to do with the individual. The individual simply is, and must function in a world where theoretical norms are superimposed.

Therefore, you have justly spoken of rights. I agree. But what is the problem with rights? We should simply be aware of them. If many persons with disabilities are not aware of their rights, they neither defend nor fight for them. I would like to draw attention to the fact that social norms are very important, because every model of disability is based on norms, and the norm does not present us with a real [variable] world, but with an ideal world, a world which, one might say, is an axiological world, which we should strive for, but there will always be 
someone who, unfortunately, will not experience it. That is a normal thing, too.

Here we have two situations: a real one and an ideal, theoretical one. It seems to me that if we really want to do something for the rights of persons with disabilities, the discussion should use axiological terms. If we discuss rights only within the framework of rights, then we are not talking about persons with disabilities. Shouldn't we rather consider how the rights of the disabled function in a world of social values and in a world of individual values? How are those values related?

\section{Rafał Dziurla}

Taking up this discussion was probably a positive step, as profound controversies have emerged. I will refer to what the previous speakers said. The definitions of a person with disability vary, and the one we should focus on is that a disabled person means "absent". Here, as we know, with reference to the disability policies - WHO 2011 - stating that: "across the world, people with disabilities have poorer health outcomes, lower education achievements, less economic participation and higher rates of poverty than people without disabilities".

This situation is mainly caused by the lack of adequate services and the presence of numerous barriers faced by persons with disabilities in their daily lives. The same report states that there are approximately one billion people with disabilities in the world, which is one seventh of the population. Some persons with disabilities use this information, they describe themselves as "thelargest minority". This is where I would like to begin. Is this a new approach? Yes and no. Because, in reference to the previous speech, where did this approach come from? Not from "higher up", not from academic deliberation, but from practice.

Perhaps some of you know about this - in 1895, ajournalist from the Boston Herald Tribune wrote that: "The spoken language and the sign 
language will be so mingled in the conversation that you pass from one to the other, or use both at once, almost unconsciously. Half the family speak, half do not, but the mutes are not uncomfortable in their deprivation, the community has adjusted itself to the situation so perfectly".

There are more similar quotes. This has been the case for 260 years, so we are dealing with a cultural transmission. This, of course, refers to a community inhabiting the island of Martha's Vineyard on the east coast of the United States, studied by Nora Ellen Groce. I wonder - if such an adjustment took place there, maybe we too could focus on the concept of "cultural fit concept".

I do not wish to claim the right to say what people with disabilities should do. I do not want to act on their behalf. But I have the right to speak for the so-called "able-bodied majority". It could be argued that the answers to all the presented concerns are characterized by the fact that we are not adjusted to them. We are not adjusted, so we can say that we live in a Majority Culture Fit, and we propose "fit to the minority". It is absolutely possible. Or it is a minority adjusting culture: "No, you adjust to us". Minority Culture Fit means that the culture does not accept different behaviors of minorities. It is considered that the representatives of the minority should adjust to the needs of the majority.

Thus, different standards of conduct are set. The Minority Culture Fit, on the other hand, accepts the differences of minorities, shows a high level of motivation to adapt to the needs of the minority and sets the same common standards for all groups. As a result, we are discussing the creation of positive stereotypes. In terms of cultural adjustment of the majority, we are creating space for communal activities, including cooperation and competition, with the creation of a single culture in mind, common to all participants. 
As far as minority adjusting culture is concerned, prejudices and negative stereotypes are created, discriminatory measures become common and the conditions for Cultural Fit Directions are established. I took it upon myself to dissect this issue. These were small studied involving employers who worked with persons with disabilities. Four factors could be identified (direction of cultural adjustment): meeting the needs, common standards, degree of integration and dissimilarity acceptance.

Finally, the results show that different areas of cultural adjustment seem to be adjusted by the type of disability, because people with different disabilities worked in different companies. So, when it comes to people with hearing loss, these modest studies have shown that we are able to adapt when it comes to accepting differences. This is clearly related to the group's prior experience. Where we are not able to fit in as a majority - I am talking here about co-workers - it adjusting to the needs. Thus, we have a situation where the study shows that, as a majority, we accept otherness, but this does not necessarily mean that we adapt to the needs (of the other).

In other words, I can understand that you need a sign language interpreter, but I might forget about providing one. I can accept that persons with hearing loss use another language, but I can put my worries about using a microphone aside.

As far as people with intellectual disabilities are concerned, it is interesting that the level of integration, namely, the close interpersonal distance is acceptable for us, as a majority. Some people say that people with intellectual disabilities are nice, pleasant, smiling - at least this is the stereotype. However, this does not mean that we are able to accept common standards of functioning for us and them. Sometimes we may think like this: I have adapted to the needs of people with disabilities.

But thesemodest studies show that its only partial adjustment, and that weadjust in oneaspect and not in theothers. As far as people with physical, 
motor disabilities are concerned - like the three groups I studied - it appears that we are able to adapt to their needs, but we do not very much accept their differences in the way they function, or in their appearance.

I shall conclude at this point, as there is a lot to talk about, but I think we should put it this way: If it were possible for the able to adjust, in almost 300 years, to a single group of persons with disabilities, the concept of a "deaf" or a "disabled" person did not exist and everyone was a part united, diverse culture, then maybe we are the ones to replicate that - I think, that the models of disability we know now will certainly not lead to that, but they may lead to the understanding of disability as a cultural minority, the most important thing is the voice of those with disabilities, that it is not so that we, the able-bodied ones, know better and soon we will create another, even better model (of disability) for them.

Weno longer want that. In the field of social psychology, the literature concerning the results of experimental studies comparing the influence of minorities on the majority is quite good. Some of these studies explicitly state that the majority would not have survived if it has not been for minorities, because minorities are more oriented towards development, creative thinking and creative problem solving. Majorities, on the other hand, are more traditional in nature and would not have progressed without minorities. If we include people with disabilities - and we must - by adjusting ourselves as much as possible to their functioning on multiple planes, we have a chance to benefit from that.

\section{Marta Abramczyk [person with hearing loss]}

My contribution will not concern theory, but reality I have personally experienced. As you know, I am a person with hearing loss, I use sign language and, at the same time, I am rehabilitated enough to speak to 
you. I would like to point out that my voice sometimes gets weak, so do not hesitate and tell me if I do not speak clearly.

I accept my - I would not even call them shortcomings - certain differences, I just accept them all. In a sense, I have to adjust to you in the same way you adjust to me.

Well, we do not have much time, so I will try to summarize my experience to convey as much meaning as possible. I suffer from complete hearing loss. I was born into a family of hearing people and, as Rafał said, as a minority I had to adjust to the majority. At first, my mom worked really hard with me. And kudos to her, because she is the reason I can speak. I started speaking when I was four years old, my partial hearing loss was diagnosed very late. It was very hard work, but I am grateful to her for it.

Then I went to the so-called school for the hearing impaired. It was a hearing loss centered school, but with some elements of oralism. Sign language was forbidden, because everyone thought that if children started to use it, their speech would deteriorate and the whole rehabilitation process would be for naught. They also managed to convince my mother that if I started to sign, our hard work would belost.

Although my mother wanted to take a sign language course from the very beginning in order to communicate with me, unfortunately all doctors and specialists advised against it, they said that it was a bad idea. During my time at the school, since we did not know sign language, we used to invent our own signs, behind our teachers' backs. We felt as if we were doing something illegal. We received, maybe not directly, but we received messages saying that we should all be like the majority. I remember many children pretended they were able to hear the TV series they were watching without subtitles, "I understand everything, I'm so proud", but they really did not understand anything.

Later I went to a school for the deaf, where sign language was allowed. I felt like I was given freedom. I could be the person I wanted 
to be. Being a bit afraid, people from our former school did not use sign language. Then, they saw how great communication can be when there are no barriers at all, you do not have to act like someone else, you just have to be yourself. In extreme cases, some have simply abandoned speech, abandoned rehabilitation and said "I am completely deaf". This demonstrates the impact that school had on their psyche and selfesteem, that they decided to take such extreme steps.

I have to admit that I also went through a similar crisis when I was using hearing aids and I felt like I was not a part of the hearing crowd, and I was greatly resentful because of that. At one point I got upset, I said that I would not go to my speech therapist, because there were no effects. I stopped wearing my hearing aids. When everyone began to bring it up to me every day, I started to put them on, but turned them off, so that they left me alone. My experience was mild in comparison to those, whose lives were truly affected by it.

I went through this change, so generally, when it comes to the environment of persons with partial and complete hearingloss - I think it is a rather diverse environment and I think it is interesting because, especially nowadays, we have two groups, or even a continuum: on the one hand, we have those who cannot hear, usingsign language, defining themselves as "we, deaf and impaired". For them it is as natural as, let's say, "we Poles", from a cultural point of view.

On the other hand, there are people - perhaps not quite like me who went to regular schools, who say that they are "hearing aids equipped" and are not acquainted with the environment of the deaf.

One more remark, I also have friends who attended regular schools, who were told how marvelously they managed to cope, and that it was good they did not choose a school for the deaf, as they are of lower quality and so on. In reality, when I got to know those people better, it turned out that they have problems understanding speech in noisier environments, despite the ability to talk in person or over the phone. 
When they visit their families and many conversations take place simultaneously, they feel lost or get tired quicker. Some simply accepted it, even though they later suffered from lower self-esteem, or were nervous that the environment did not fully comprehend them, mainly "How can it be? He does not like family gatherings? How dare he".

Sign language is demonized and persons with hearing loss are forced into the world of the hearing. The worst part is, they have to pretend to be someone they are not. I have a cochlear implant and during the conference, if I focus enough, I understand what is being said to me, but there must be absolute silence and no noise, and I still get tired quickly. Many people cannot understand that when I come home from work, the first thing I do is turn off my hearing aids and enjoy the complete silence, which is natural for me. And I can't imagine going out all day with my hearing aids on. I have a boyfriend who also can't hear and we only use sign language. We and Adam create a unity, a cultural minority.

\section{Maria Stojkow}

I will approach the issue from a completely different perspective. I became interested in the media discourse on disabilities, but I am referring to a particular discourse, since I am concerned with media reports on Muslims with disabilities during and after the refugee crisis. The unrest that has shaken the entire Muslim world has often caused families to fall apart. This is extremely important because institutional care does not exist in the Muslim world. When a person is born or becomes disabled, they only receive help from within the family. When the war broke out and families were separated, the situation of people with disabilities became very complicated, especially for those who were sent to refugee camps.

In my research I focused on the Polish media discourse from 2004 to 2018. I have analyzed all the news sites, websites of all the 
newspapers and, to a much lesser extent, social media. These were not as relevant because they basically repeat information that comes from other types of media. I used Google to search for various phrases concerning disability, for instance, "aiding Aleppo", "aid for disabled Muslims", "aiding Syria".

It appeared that there is very little information about this phenomenon and it is very clear how differently the topic is approached depending on the political situation in Poland. In 2014 there weren't many of these articles, but the manner in which disability was addressed was completely different. However, the time of the refugee crisis coincided with the change of the political landscape in Poland.

At that time, the narrative about disabled Muslims was concerned with aiding a place or an individual. Frequently the information focused on a non-governmental organization, very often connected with the Church. Bottom-up initiatives, such as the willingness to sponsor the arrival of persons with disabilities in Poland for treatment, also appeared. It is very clear that, until the end of the refugee crisis, such initiatives had occurred and were received rather positively. After 2014, this discourse changed dramatically and the information was presented differently depending on the media.

\section{Elżbieta Zakrzewska-Manterys}

Who would like to comment on the first round [of the debate]?

\section{Marta Sałkowska}

The first thing that comes to my mind is that we need these debates, not reports, but debates in which various views will collide, where opinions and experiences will be exchanged. The concept of cultural minority and the cultural approach to disability and persons with disabilities is 
greatly inspiring. It seems to me that in our sociological thinking the perspective of the dominant culture and the minority culture is extremely important. It is important to look at a disability from a cultural perspective of the able-bodied majority and how it can adjust to the disabled minority in onder to facilitate their way of life. To not tell them what to do, what model to adjust to, but to allow these minorities to live the way they want to.

\section{Krzysztof Pezdek}

The cultural aspect of the issue was well addressed, which immediately made me think. The idea of tolerance was also established so that the majority could discipline the minority and refuse them the requested rights. Generally speaking, tolerance is a very clever tool for managing a society, because we allow minorities to function, but only within the limits set by the majority.

\section{Elżbieta Zakrzewska-Manterys}

The enlightened majority.

\section{Krzysztof Pezdek}

This majority adheres to specific standards, drawn from various branches of science. So, there is individual freedom, but the limits of that freedom are set by the majority. And we will continue to exercise our individual freedom without conflicts as long as we are tolerated by the majority. 
Agnieszka Woynarowska

I have two issues to address. There is a school for the deaf in Wejherowo, where students do not sign, but learn to speak. It was believed that the sign language would makeit more difficult for children to adapt to hearing people. Therefore, some thought that spoken language is a blessing for children with hearing loss because it enables them to function well in the hearing world. I observed children signing behind their teachers' backs because it seemed natural to them.

That attitude of the oppressive majority, but in a caring environment discourse. We (the majority) try to include them, in our concern for the future well-being of those people. They are supposed to integrate with us (the majority), but on our terms.

The second issue is this: Analyzing many aspects of dealing with people with intellectual disabilities myself, I am confronted with these terms. We have given people with disabilities the right to be active, to work. These rights, bordering on coercion result in the attitude which can be summarized as - you must be active, you must go to work. All the gears of social policy start turning, along with various EU projects we will make you active, we will invite you to said projects because you have the right to work, therefore we will do everything in our power to make you work. A lot of people of course benefit from that.

However, for many people, especially those with intellectual disabilities, these projects are ineffective. These people are interns, but they also maintain projects which, thanks to these beneficiaries, function because the project is happening, there is a client, they became an intern. Nothing comes out of it afterwards, but that is another matter.

And as Professor Zakrzewska-Manterys wrote, we lose our consent to such an alternative way of existence. You can be active, or you can be inactive. Who are you and who do you want to be? This is the consent 
to this free "non-normativity" about which Prof. Zakrzewska-Manterys wrote in one of her books. How do we tolerate, allow? But do we allow people with Down's syndrome to be "non-normative"? This is where the terms emerge: normativity - non-normativity.

Jolanta Rzeźnicka-Krupa

Marta [Abramczyk] has already told us how oppressive practices can be used against persons with hearing loss. I am a teacher practicing critical pedagogy and, in this field, one of the key categories is hope. If we want to change something, we have to believe that it will work. If we do not believe, nothing will change. If we have a desire to act, we can do it. Hope is therefore essential. I am also extremely close to the cultural approach and the concept of cultural minorities, but in the context of biodiversity.

From this perspective, the model of social disability, which is criticized by the persons with disabilities themselves, does not consider individual experiences and needs. This model is founded on the basis of a negatively valued deficiency. The minority group model combined with the affirmative approach does not treat biodiversity as something negative, because then we automatically engage in the discourse of oppression. One should only look at the possibility of building a positive identity of a person, which can be realized in various aspects of life.

\section{Milena Trojanowska}

I would like to go over the various points that have been addressed. I will start with the last one, which is the fact that deviations from the norm aren't valued. I think that we should look at the category of norm a little differently, which, as you mentioned, is and will remain active in our environment. 
Norm as a philosophical idea is a bit closer to me. Somewhere, there is a category of an idea as a model for a specific target, which is later exemplified in various examples. Here as well, biodiversity is a category which can be included in a certain discourse about disability, the exemplification of biodiversity in our society, without valuing it, and merely approaching our biological nature and our physicality as a societal diversity. I do not believe that the discussion concerning independence, independent existence and social value must give rise to conflict.

Marta mentioned that an independent life can have a wonderful impact on various social values and on the huge contribution of the cultural minority - the persons with disabilities. I just wanted to briefly tell my personal story, because it connects all the mentioned issues together perfectly. I am an academic, but I also live with a disability. My parents agreed that they should adjust to me, and not the other way around. They allowed me to live an independent life, which was very expensive, but thanks to that my social contribution is much greater than if I had stayed at home.

\section{Elżbieta Zakrzewska-Manterys}

I can see Mrs. Magda wants to share something with us.

\section{Magdalena Kocejko}

I would like to present a critical view on the minority perspective, as I believe that it has its limitations. The perspective that is closest to me concerns the functioning of the state, social support, the dominant way of thinking, and the policy relating to disabilities, which I consider something more than an institution. If we adopt the minority perspective alone, the intersectional character, which, for example, emerged in the stories about the disabled Muslims, is lost. 
The topic of women with disabilities also escapes us. I mean all situations where disability is intertwined with other aspects of life, where someone is repeatedly discriminated against because of their belonging to several groups. Disability is not permanent, but - as Professor Wysocki, already mentioned here, stated - one can acquire disability, be born disabled or live long enough to become disabled.

At this point if we adopt a minority perspective alone, then, firstly, we assume that all people with disabilities feel disabled. This is not the case, because for example, in the analysis of the situation of people with disabilities conducted in Warsaw, it was found that the majority of people with disabilities there are elderly people and do not have to define themselves as disabled. That is one thing.

However, from the level of minority - majority politics, the rights bordering on both sides elude us. For example, the rights of women with disabilities, who are invisible in the feminist movement and are also considered radical for a significant portion of the disability rights movement. These are lost somewhere. Hope, which was addressed here, was something I wanted to address, as it is a category close to me as well. I would not call it a utopia, nonetheless...

Krzysztof Pezdek

This is an existential category.

Agnieszka Woynarowska

A reference point. 
Magdalena Kocejko

Personally, I hope that our society is not overtly ableist. I hope that we all function in the society, and that the norm is not defined by the ablebodied majority. Instead, diversity is the norm.

\section{Rafał Dziurla}

May I respond directly to Magda? I agree with most of what you said. However, what you said about adjusting to diversity is one way to go. To achieve that diversity, we must fully adjust to various minorities and listen to their voice. It will be inconvenient. We must leave our comfort zone to create on for others.

Not just for persons with disabilities. The cultural interpretation introduces a large area of intercultural or cultural research. Blended biculturalism is one of the terms used in said research. Studies show that if there are people living in the majority culture which assumes positive practices, certain phenomena appear which do not belong to either the minority or majority cultures. If mechanisms which cannot be traced to either one of the groups arise, then this is the path we are now taking.

As Professor Brown said, "I am from a minority culture and my identity is positive". I was shouted at for this statement at a conference in Lublin. A certain rehabilitation professor said that he will not accept anybody who considers disability a positive thing. This was a man who lived by the quote, which created his culture of disability: "if they took my disability away, I would not know who I am". [Disability] is his positive identity. Disability can be an attribute seen positively.

Finally, I want to tell you about my psychological experience. There are few people I work with at the ECHO Foundation, they are adults who were left without psychological assistance when they were 
becoming disabled. It is perpetual tragedy. Here is my proposal, would not it be better to treat disability not as a deficiency but a trait? Same as eye color, height or our appearance.

Thus, we end up with something only called disability, but treated as a trait. I must say that one of those people said it was liberating, it was something she was searching for. Now she can use it as something to lean on and be more confident with other people. It can always be rationalized, like she said: 'It's how I wanted it to be, sometimes I feel better, sometimes worse, but it is still my trait". Therefore, it is useful for those people.

\section{Elżbieta Zakrzewska-Manterys}

But the mainstream, the general discourse on disability, goes in the opposite direction. Hope? I am against hope. Because hopeis a constant suggestion that the present state is poor and it must be changed. But why? Isn't it better to just see the positive, good sides of the present? I am a Durkheimist. I am against free will. I believe that the so-called free will is a social phenomenon and exists solely because there are adequate social conditions for it to manifest itself.

But look at what is happening. Why is the phrase people with disabilities $^{4}$ being promoted now? Linguistically speaking, it is really clumsy. It stands in contradiction to what Rafał Dziurla said. This political correctness proves that disability is a burden, that beauty and human dignity are intact despite disability. That it clings to people like a barnacle, and yet they are beautiful in spite of it.

What you said is the opposite. A person is beautiful because of the disability. Public discourse contradicts that. The direction we took leads to greater rationality, and greater distancing of the disabled from us.

\footnotetext{
4 Translator's note - in Polish “ludzie z niepełnosprawnościami” is a linguistically awkward phrase.
} 
Our discussions about humanizing the disability may be treated as intellectual tickling. People do not think like that.

What Agnieszka Woynarowska said about deaf people, we see their oppression when they barred from using the sign language, but I am not sure if that oppression isn't even greater now. The parents of deaf children are told to immediately perform implant surgery. After all, movements promoting implants are becoming increasingly popular. It seems that deaf people are no longer allowed to be deaf because they have to use implants. Therefore, the reality of the deaf is controlled. They are subject to what the parents of intellectually disabled would like to do as well, but unfortunately, or maybeluckily, there are no technical possibilities for that. Are you familiar with the relationships of parents and their children with Down's syndrome? They are tragic. These children are treated like prodded cattle. It is a lot worse than 20 years ago, when my son was little. I did that as well, but I had fewer technical possibilities.

Now the parents are training these kids, morning to evening, so that they won't have Down's syndrome. What if my son has full-blown Down's syndrome because he was rehabilitated incorrectly? My children won't be like that.

What do we do with ordinary children? Normal children? The same thing. Only normal children will rebel and say: "leave me alone". The mentally handicapped will say nothing because they're more susceptible to other people's definitions. What Rafał postulates is to not impose our own definition on them, but I come from empirical social sciences.

For many years I've been taught that the world has an empirical nature and we need to study the so-called facts. The more I look at these empirical sciences, the more I come to the conclusion, that if someone has a right theory on a subject, then no fact is able to disprove it. That's what Mrs. Marta said. Everyone could clearly see that prohibiting sign 
language is bad for deaf people, but their theory was so strong that they still did it.

So, I am cautious when it comes to hope, because this is our hope. All that with that post-enlightenment mannerism, that we are better than the disabled and we wish them well, gently patting them on the head at the same time.

And what Maria Stojkow said about Muslims, how it shows handson that disability is a social construct and tells us more about us, who use this concept, that of those poor souls we tarnish for some theoretical and scientific reasons.

\section{Krzysztof Pezdek}

I had the impression that we were discussing culture as if we were able to live outside of it. Right away I did not like it, because it is impossible to live outside of culture, so - overall - disability is a $100 \%$ cultural product, just like the norm and everything we experience directly through consciousness. Nature is there, but welive in the world of culture. As long as we are aware, we are in a culture and we try to alter it.

I would agree with Professor Zakrzewska-Manterys that we have to function in the situation we are stuck in. I have analyzed the norms and what is characteristic of all norms is that they are conventions and that they can be subverted and transferred. What is a disability today may not be a disability a moment later.

This is the case with, for example, Down's syndrome. At first Down's syndrome was stigmatized, and now in some scientifically and technologically developed countries it is not considered a disability. Here, the norm is subverted. On the one hand, there is Down Syndrome, and the norm is what the syndrome is not, and on the other hand, there is Down Syndrome, which becomes the norm and escapes nonnormativity. 
The norm can be also transferred, which is even worse. If we say that people with disabilities can be helped, then the norm is transferred from the sphere of aid to the sphere of economics, and we can say that there is no money. We would very much like to help, but we cannot for financial reasons - but hopefully, and as soon as we find the funds, we will immediately allocate them, for example, to adaptation programs for the disabled. Or it is transferred to the religious sphere and we say that it was God's will, and you cannot oppose God. This is how disability issues are transferred to areas where they cannot be solved.

Agnieszka Woynarowska

I'd very much like that to be the case. In general, the concepts of biodiversity, neuro-diversity, Down's syndrome, intellectual disability, these are different facets of human existence. Some time ago I analyzed the Internet discourse [on the subject]. I know that it is peculiar and the comments that appear on the web are also peculiar.

However, I have read the article titled The lives of mothers with Down's Syndrome children and I read the comments. It was a long discussion, there were about 400 entries. I analyzed the discourse. There was a numerous group of Poles who treat Down's syndrome as abnormality, as a good reason for abortion; that giving birth to abnormal children is immoral; that if someone agrees to give birth to an abnormal child, then they should pay for their rehabilitation; that the more numerous sick people are in society, the more the society is sick. These are the things people wrote. I believe that we are somewhat at the crossroads, as a society striving for tolerance and biodiversity, that there are no able-bodied and disabled, we are all varied. 


\section{Marta Sałkowska}

I would like to make a short remark in reference that we do not live outside of culture, norms and values. When I interviewed the mothers of children with Down's syndrome, one Norwegian woman told me: "We had to make it normal, that she was not normal".

And one more issue concerning the process of bringing children out of Down's syndrome and disability, as well as "over-rehabilitation". I found out, from the interviews, that the children were so heavily rehabilitated that they could not move their arms, legs or heads. They were tied up, and they even had a roller under their chin to support it. All in accordance with specialist recommendations. Women, in fact, are forced to juggle between various roles at a high pace, and have no time to be mothers, because they are rehabilitators and speech therapists, because they feel that these professionals, omniscient specialists, really want the best for their children and that all these, sometimes absurd and mutually exclusive, recommendations have to be implemented.

\section{Krzysztof Pezdek}

Because that's in their interest.

\section{Elżbieta Zakrzewska-Manterys}

Because they're hoping things will get better.

Jolanta Rzeźnicka-Krupa

It seems to me that we can also understand the concept of hope in different ways. Mothers, who are therapists, hope that the child will become "normal". However, I referred to the category of hope not in 
relation to the ability of normalizing or rehabilitating someone, but quite theopposite, in relation to the possibility of social change, namely, that we, as a society, will learn to think differently.

\section{Elżbieta Zakrzewska-Manterys}

We are not going to learn. Look at the issue of implants.

Jolanta Rzeźnicka-Krupa

But it is not the case that everyone, everywhere wants to use implants for those with hearing loss.

\section{Elżbieta Zakrzewska-Manterys}

How is it not the case? Of course, they want to.

Jolanta Rzeźnicka-Krupa

There are people who can oppose it. They'l say "leave us alone". Professionals, however, are struggling to maintain their own interests. It's their profession, it's money, it's different programs.

\section{Marta Abramczyk}

Speaking of implants. Indeed, an increased emphasis on implants can be observed. My story was not proposing their prohibition. My point was to give them [people with hearing loss] - on the one hand - an implant or whatever, but also, on the other hand, a freedom of sorts. If they feel alright among their own people, why should that be forbidden, only to plunge them into the world of the hearing. I've seen cases like 
this myself. At first, my mother also tried to force me into the world of the hearing, because everyone told her that if I stick to deaf people, I will remain deaf.

\section{Elżbieta Zakrzewska-Manterys}

To be a socialized member of society. This is what the society demands.

\section{Marta Abramczyk}

Exactly. I hope you understand this is not a search for the golden mean. I will say something, which may sound a little strange. Only yesterday I realized that being among the hearing is very tiring for me and I just need to take breaks from it. Breaks from the world I have to adjust to. Others also have to adjust to me, which is also difficult.

Many deaf people have an issue with forcing the hearing person to repeat themselves, then they feel stupid and pretend they heard was said. It's a very common phenomenon. And you need a break from such situations on your own terms.

Despite all appearances, I noticed that when I began switching places, I started to have more energy to act in the hearing world. Working in the Polish Association of the Deaf turned out to be a blessing, because it's a place free from barriers and I can act on my own principles there, and I have more energy to attend conferences and meetings like this one, meetings with those with hearing loss. I also teach sign language classes. Earlier, in the kindergarten, I had to put a lot of effort into what I was doing. I had no energy left, I was tired, not only mentally but also because of the effort put in.

Now I can take a break and feel like I'm a normal person now, and I'll be a normal tomorrow, in my own normal reality. Every world has its barriers, you just have to look for a solution. It's more about balance. 


\section{Elżbieta Zakrzewska-Manterys}

In order not to struggle.

\section{Milena Trojanowska}

Firstly, I would like to refer to what has already been mentioned, namely, people who live in mixed groups, where minority and majority cultures intertwine. My own research suggests that the functioning strategies that are being developed in these groups are the most effective from the perspective of the society and biodiversity.

Besides, in my opinion, biodiversity should be highlighted in the categories of co-existing ontologies, as the biological category is the factual reality. Our physicality is a fact and all the models of disability that emerged later were socially constructed - they responded to a given state of the society, to particular needs. That is why I believe we use that the awkward phrases such as "person with a disability" or "people living with multiple sclerosis" and not "people suffering from multiple sclerosis" or "patients".

These categories have been extremely useful in certain periods and environments. And the fact that this social model and the associated category of people with disabilities have been somewhat exhausted shows that we should construct a new model which will respond to new needs and environments, a model which will be embedded in our reality. Was that model bad? In my opinion, we should notlook at it in terms of values, but in terms of our current reality in which we function and say that it is no longer useful. 
Elżbieta Zakrzewska-Manterys

I'm not saying it's wrong, I'm saying it's completely irrelevant. This is an academic discourse.

Milena Trojanowska

It mattered because it translated into policies, action and into the adaptation of space.

Agnieszka Woynarowska

If I may, as numerous issues have been presented, I'm thinking we should focus on the present, on the status quo.

Elżbieta Zakrzewska-Manterys

But what for?

\section{Rafał Dziurla}

This is how psychology and psychotherapy work. You have to come to terms with reality. With the status quo. With the difficulty construing reality. You said a new model needs to be built, but let's do it together. That's why Marta's here, we're in this together, so let's do it right. What issue makes it difficult to do it together? You spoke about hope, that we have hope, but I do not know where to get it from.

I sometimes say, colloquially, that persons with disabilities are used like batteries (sic!). Like in the Matrix - the disabled are seen as a source of money, income for a very large number of parents, caretakers, specialists, as well as researchers (we do receive grants for our research). Then we conclude that it's even more ethical. 
However, we don't discuss the situation in special schools, and we require complete criticism and a radical change of the people who work there, a change in the mindset and a change in what is happening there. There are a lot of groups, simply put. There are many groups of interest that want to maintain the status quo.

We are talking about change, let's us move on from theoretical discourse to practice. The situations mentioned earlier would not have happened had we realized that, since nowadays, according to our statistics, about $20 \%$ of people in Poland are disabled, so they should be represented in every group: at work, at school, in public space. The distribution in the society should be proportional.

Of course, this is not the case, but if it were the case that my boss is a person with a disability, if the Prime Minister or a Minister were a person with a disability, if there were $20 \%$ of people with a disability among my friends, I would carry on with my life alongside them. I would party, develop and do things together with them.

It's the same in sciences, if there were students, rectors or deans with disabilities, the barriers we discuss would not exist. They would be gone. But, of course, there is yet another aspect we have to look at and, as a psychologist, I have to draw attention to. Doctor Tomaszewski (a professor from my psychology department), who is deaf, discussed internal oppression - audism, in this case - and the fact that we shouldn't say "no worries, I'm right behind you" to those who are disabled and push them towards activism and building barriers.

We have to give them space. And that's why I was talking about adjusting, because that means we're giving them space. For instance, one theatre stages a play One Gesture (Jeden gest), there's an opera for the deaf, or Teatr $21^{5}$. That's it.

We, however, offer nothing. We have powerful groups of interest which could function even better, but they are not yet aware of it. All

5 Translator's note - Teatr 21 is a theatre for actors with Down's syndrome. 
manufacturers of rehabilitation equipment, global companies with powerful capital, implant companies, for instance. It is said that implants are fine. It is said that even if one has a minor hearing issue, they should use an implant. But what is not said, is that they can hear [with the implant] only in the frequencies and intensity of human speech and only in conditions, as Marta Abramczyk said, close to perfect silence. It will not allow her to participate in social life. I don't know if there'll be room for practical advice, practical action?

\section{Elżbieta Zakrzewska-Manterys}

I don't know, it's hard for me to say. These contradictory tendencies, they will always exist because there are different interest groups. We live in a therapeutic discourse. I am not only concerned with companies which offer technical equipment: implants or wheelchairs etc. and profit from it, but also with therapists, humanistic psychologists, special educators who, as professional corporations, tell parents that through rehabilitation their child will be normal. Before these parents understand that a child has a disability, they spend significant amounts of money for different speech therapies (I am an example of this), different technical measures and other efforts. No one will tell such a parent that the child is disabled and will be disabled. It is not unrecoverable. People hope that, through these measures, their child will be less disabled. As a result, I think that we all talk about the same thing, but not really.

It's like a family gathering, where everybody talks about their own illnesses. We all use the word "disability", but everyone understands it differently. Even ifitisn't said explicitly. Rafał and Mrs. Martaimmediately raise an issue of those with hearing loss, Mrs. Magda addresses citizenship, and others swerve towards oligophrenopedagogy, and yet subjects of 
special pedagogy, a really dynamic discipline, are virtually non-existent from the statistical perspective.

This is because they aren't numerous, merely a few percent of the population. Who cares about them? After all, the Convention on the Rights of Persons with Disabilities is concerned with them, but not really, because they are the exception. This way we can hide in the closet. Naturally, I support married couples with disabilities, and of course I support the abolition of incapacitation, but on 19.09.19 I am going to court to legally incapacitate my son, because it does not apply to him, because he is an exception to this rule.

This shows that, firstly, disability is a social construct and secondly, it is an umbrella term and it tells us absolutely nothing about people with disabilities. It tells us nothing, because it doesn't address the psychophysical relations between those people, they [different categories of persons with disabilities] have absolutely nothing in common. This word [disability] speaks more about us, the users of the language, rather than the designators of that term.

Katarzyna Król

Our group, which is not very representative, discusses people with, firstly, intellectual disabilities, somatic disabilities (in wheelchairs) or sensory disabilities. I agree, if the people who are able-bodied, the mainstream society, will adjust, then many things will change. I started observing the community of people with degenerative diseases, sort of from the outside, as I am not suffering from the disease myself.

People with those diseases rarely live past 25 years old. It's a slow death, they admit themselves. They don't discuss adjusting, they think about matters related to education, because they are often very bright people, intellectually. For them the concept of adjusting is not relevant to us, even to me, despite being in a wheelchair, because their disease 
means an every-day struggle for what is important for all of us - life. They fight for their every breath and heartbeat, they talk about this. They think about it, and it is impossible for us to adjust to that. It is the same with people with intellectual disabilities, we will not adjust to them. We can adjust to peoplein wheelchairs, as it seems it is something that is easier to imagine. We can sit on a wheelchair, we can close our ears, we can close our eyes, and then we become disabled.

I cannot imagine the life of the Professor's son, because it is a completely different way of functioning, and I will not be able to adjust to it. There's one more issue. Of course, people with disabilities want to function together, but I am afraid that if we start talking about the broadly understood standardization of disability, then our environment will not adjust quickly enough. Architectural, Internet and everyday barriers will not be adjusted. If we normalize the concept of disability, our society and the environment, will not be able to keep up, let's say, physically. Then we start ignoring the disability, we'll see the other person and conclude that they function and live alongside us, but the barriers will remain.

People with disabilities also mention financial barriers, they want to work, but they can only work in big cities where they have opportunities. Many people do not have such opportunities. Many people are not even able to work at home because companies do not want that. It seems to me that normalization has its dark side.

\section{Krzysztof Pezdek}

What Kasia Król said about lack of normalizing is being normalized, because this is the world we live in and there is nothing we can do about it. We should, however, have humane approach towards norms, that is, norms can be broken, as the Professor said: "I'm against legal 
incapacitation, but I do it too. Why? Because I think it's the right thing to do".

We should give everyone the right to break norms, because norms don't comprise social diagnosis, norms are an ideal state to pursue for those who want it and those who don't want to - don't have to.

Simply put, the norm does not delineate what is mandatory, it is incidental. If we treat the norm as incidental, then the world of our experiences will become normalized, as nobody will impose anything on anyone. We will be able to exercise our freedom within the limits of the norms we have adopted, but if I find it useful for me to depart from those norms, I can do so.

And, of course, law will definitively draw the boundaries. I do what I want, but I do not break the law, because then I would succumb to the "dark side" - hurting others, committing crime, doing something socially undesirable. But within norms, whether we accept them or not, we should have absolute freedom and we should do whatever we want, guided only by our own system of values. I am not hurting anyone and it's only a matter of moral values, so why wouldn't I do what I want?

However, I still know that the norm is different. So, for instance, if I eat sugar I can be obese and I can lose my sight, but that's not necessarily the case, because my body can ingest sugar in such a way that my eyesight will become even sharper. I bear the full risk and consequences for this.

Agnieszka Woynarowska

This is the right to freedom of choice. 
Elżbieta Zakrzewska-Manterys

Mrs. Magda, when we began with your speech, it appeared as though we were headed towards deep theoretical analysis, but we arrived at practical discourse. Back to theory, then.

\section{Magdalena Kocejko}

I would like to return to the issue of rights, because I have the impression that we put the category of rights separately from human rights. We started with the formulation of human rights, and again, when discussing human rights, we turn towards civil rights, then towards pure freedom, forgetting the fact that human rights are something extremely complex and affect all areas of life. The very concept of the Convention on the Rights of Persons with Disabilities came into fruition because of them, and the entire great movement for people with disabilities fought for it because human rights in their original version were not inclusive. They did not protect the rights of people with disabilities, because they did not perceive these needs as different, and that this group is very diverse.

That's one thing, there are also needs which are not fulfilled and rights that are not protected by European Convention on Human Rights. For example, the right to independent life which simply does not exist in the Convention on Human Rights. A violation of this right can only be when confronted with disability. I think that state action concerning human rights is very important. We thoroughly discussed the fact that there are large interest groups, that the state is doing something or claims that it is not complacent, we know that it's always the case. If we cast aside these human rights categories in our mindsets, also concerning disability, we will be provided with a stronger, more 
practical tool for thinking about this matter in relevant areas, for instance, the whole issue of independent existence.

I would nevertheless like to refer to the fact that the Convention on the Rights of Persons with Disabilities itself was a light at the end of the tunnel and, at the same time, a new instrument of oppression. It has become a tool of oppression because it has unearthed the discourse related to activity, to civil rights, and omitted the fact that people with disabilities are often simply poor (economic aspect). Because of the Convention, since our admission to the EU, we have been receiving EU money, which swung professional activation and rehabilitation into full gear, taking productivity as a norm while failing to notice the bigger picture.

\section{Maria Stojkow}

I would like to say that we have a problem with the acceptance of otherness. I work with Muslims in Poland and abroad, and I am highly interested in disability in a cultural context. What struck me when you mentioned the discourse of people putting vile comments concerning those with Down's syndrome, was the way people describe intersecting qualities, such a disability, and for instance, a Muslim person...

\section{Elżbieta Zakrzewska-Manterys}

- Or a homosexual with a disability, for that matter -

\section{Maria Stoykow}

... create a category of absolute exclusion. The problem is that, as I read these articles, I can only assume that their authors had good intentions, but the way they wrote about the disability of people from other cultures 
means that we are faced with a combination of an oppressive and neocolonialist discourse. That disability is always described in terms of aid. Even if there are programs, there is a better-knowing of the able-bodied part of the West. Disabled people from other cultural backgrounds are described in the same way as people who are totally incapacitated. Regardless of their condition, people with disabilities are also stripped off all the attributes of social life because they come from cultures that are simply worse than our own. In the Middle East, marriages of close relatives are often the cause of disability, which is sort of their fault, and this is why the media, often Polish, describe it that way. If they have not yet understood that these types of marriages are inappropriate, then their social situation is the result.

Let's consider genetic disabilities - I saw, in several outlets, an assistance request for a girl who was born without legs, and in the Polish media, people had trouble understanding her condition and the fact that she was born this way. The stories surrounding her were about something completely different. A picture of this girl appeared in social media in some country and someone was collecting money to help her. Her dad made tin can shoes for her to help her walk, but almost all Polish media (only one outlet indicated that she was born with the disease) connected her condition with the result of warfare, they thought she lost her legs in an explosion. This is the narrative accepted in Poland, the only one that is understood. Here, this exclusion, due to disability and cultural differences, intersect. What needs to be changed is to make society more sensitive to otherness.

\section{Rafał Dziurla}

This cultural aspect is useful not only in Poland, in Polish culture, in the majority culture, which is determined, or self-determined as disabled or diverse. There is hope that the culture we live in, that is, the global 
culture is multifaceted. What you have said is interesting, and it also falls within the area of my interests, in particular, the issue of the interpretation of disability in different ethnic cultures, where differences are significant.

This is a practical aspect, but I met a Ugandan pastor at a conference in Austria organized by the Association of Parents of Deaf and Hard of Hearing Children and he spokeabout his project to establish schools for the deaf. I asked him how he builds them, since disability is treated "fairly harsh" in Uganda, or in other words - these children are abandoned and nobody takes care of them. How did he convince the parents to send these kids to school? The Pastor answered that in Uganda there are (he stated how many), let's say, 150 tribes. He said that the deaf are the 151st tribe, and they understood it immediately.

This is natural thinking, not only in academic discourse, people talk about it worldwide. The culture of the disabled is, in a way, a diaspora. Most people with disabilities are born among the able-bodied who know nothing about disability and have yet to learn about it. This is opening up new fields of research. The culture of people with disabilities, thanks to the Internet, is global and it turned out that, as Professor Brown said, we share some common characteristics.

They do not like us everywhere, we encounter oppression everywhere, we are limited and forced to various things everywhere, this is the experience shared among people with disabilities, whether they live in the United States, in Poland, Japan or India, or in ethnically diverse cultural areas. Studying, but also practicing the various actions resulting from these studies, because this broadens our boundaries of cultural understanding, and what its nature, because if it is not ethnic culture, then we must redefine the concept of culture we have been using until now. This is a utilitarian portion of it all. We may benefit, but only if we open up to other areas. 


\section{Milena Trojanowska}

I would like to contribute to the practical aspect, but in a theoretical way. In theory, I assume that although these definitions are socially constructed, in social interactions these they are still subject to interpretation. We can also consider the implementation of what we managed to elaborate among ourselves. I think that the possible methods of implementation should have been mentioned yesterday, at our Section's meeting.

It seems to me that in some way this is already happening, because Rafał is a member of the foundation, Magda is an activist, many of us are active in these fields. But I think that our activity later reaches society, through our interpretation of definitions. I cooperated with Magda in creating a report on the availability of gynecological examination for women with disabilities. This has translated into a practical implementation in hospitals. It also had an impact on the social understanding of this demand, because in other own research focus groups, somebody else mentioned this report.

It was both women with disabilities and men who said that their wives had read the article and told them about it, and then they discussed it with their friends. Therefore, our actions have a reach. We can have a real impact on how disability and needs are defined and interpreted.

\section{Elżbieta Zakrzewska-Manterys}

I would like to, if I may, ask Adam Stoyanov to comment on our discussion. 
Adam Stoyanov [speaking in the Polish Sign Language, Marta Abramczyk translating to Polish]

He would like to share his own view on disability. His family has been deaf for generations. Parents, siblings, grandmothers, uncles and aunts are deaf. They are not having issues functioning. They are not in any trouble. They do very well on a daily basis. Adam admits that he has little knowledge of Polish because Polish Sign Language was his first. When a deaf person lives with the hearing, they acquire the knowledge of the Polish language by watching TV. At his school, some pupils were using implants, and some did not. In his class, there were fewer students with implants, some did not wear hearing aids/speech processors. For example, there were twin brothers who had implants but did not use them. These implants were there to meet the expectations of the hearing, because the hearing impaired understood little.

Adam tried to establish contact with the hearing, using simple written Polish or gestures. I (Marta) will add, that when we were in China, Adam was more able than I, because he was better at communicating with the Chinese through gestures than I was using English. Pawel, for example, he wasn't understood by the waiters when he wanted to order something without fish. So, he (Adam) took out a piece of paper, drew a fish, crossed it out, drew a pig and showed a "great" gesture. And it worked. I would like to add, that what Adam showed us in this case is that, for the deaf, the barrier is not the hearing loss itself, but the hearing majority and the way they function.

There was a performance called Opera for the Deaf, which told a story of an island inhabited by the deaf. When a hearing child was born there, it was perceived as sick and to cure it, it was necessary to damage its hearing. It was shocking for those who could hear, but for us, who couldn't - it wasn't. In many cases it is us, the society, though 
unconsciously, who create our own barriers. As I said, Adam's family functions without any trouble. Let me tell you about the doorbell. Adam's parents live in a detached house and there was a problem with the doorbell. You could never know if anyone's coming, you also can't hear the bell.

So, they came up with the idea of installing automatic lights in other rooms, so that they turn on when somebody entered the house. They essentially created a light-based doorbell. They try to solve their own problems themselves. Their only serious problem is mastering the Polish language. Adam is learning Polish.

Adam Stoyanov [translation by the Polish Sign Language translator]

In Signed Polish ${ }^{6}$ everything which is written needs to be signed. It was supposed to reflect the Polish language. It hasn't been understood very well by those with hearing loss. Communication is a little different, too. To be understood by the deaf, you need sign in their natural language, PSL (Polish Sign Language).

\section{Marta Abramczyk}

The PSL is a visual-spatial language. Adam is a master of that language. He can describe every scene of a film in this language so precisely, with so much detail using just a few signs, which in Polish would have to be written on many pages. Deaf people have the ability to sign pictorially.

When Adam describes a film to me, it's like watching it myself. There are schools which teach bilingually, where natural sign language is the basis, and he is there to explain the grammar and meaning of Polish words to a person with hearing loss. The Polish language is treated

\footnotetext{
${ }^{6}$ Translator's note: Signed Polish and Polish Sign Language are two different systems.
} 
as a foreign language. For Adam, this method of teaching would be perfect, as he would then be able to learn and understand quickly.

Some teachers at his school were unable to explain things, as they only used Signed Polish. Unfortunately, there are no bilingual schools in Poland. They do exist abroad. Adam wishes that such a school would be established in Poland. He hopes that children will get the chance he didn't have.

\section{Elżbieta Zakrzewska-Manterys}

It was a beautiful showing of the nature of cultural difference. What comes to my mind, is this. People with mental disabilities - who were referred to as "mentally retarded" for a larger portion of the $20^{\text {th }}$ century - can be considered a prototype for a modern person with disability.

This is the norm. There is only one norm, Vygotsky. All people have one path of development, some reach its end, some are worse and stop earlier. This is why they are considered retarded, or handicapped. These are all expressions from the $20^{\text {th }}$ century, showing that there is only one way of being a normal person. And all the others who stand out need to work harder to be reach the norm.

I raised these issues in Wrocław, at a conference held by the University of Physical Education. During the break, one lady comes up to me and says: "Professor, I'm a kindergarten teacher and I use the 'mentally handicapped' phrase, is it wrong? What am I supposed to say?" You have to say that, because it's the Polish language. However, we must be aware that this is merely a language convention. It's not an empirical fact, it's an agreement.

This is a first-hand account showing how our agreements can be harmful to people, how we force our ideas on them, because we think they are the best in the world. Nothing could be further from the truth. 
Mrs. Marta showed us how much more limited our language is, but we do not have the same tools as Mr. Adam to create such complex images.

Katarzyna Król

When it comes to the issue of sign language, I think that if we all used it, the problem would disappear as far as hearing disability is concerned. In this case, the only problem is communication. Other disabilities have it worse. I often talk about barriers associated with the wheelchair. Some time ago I came to the conclusion that architectural barriers actually affect the majority of the society. You can consider a mother with pram, elderly people, tourists with suitcases, I really started to wonder why the stairs and all these thresholds? Driveways and elevators are more practical for everybody.

Jolanta Rzeźnicka-Krupa

Speaking of stairs. A few years ago, I was at the University of Lisbon and there were no stairs in the conference building. There were only slight ramps. As far as our discussion is concerned, I would like to thank Mr. Adam for his contribution and I think that our understanding of the norm can be broadened and filled with other content.

Finally, I would like to mention Jacques Rancière, a French philosopher, who often discusses fundamental equality. How would our world look like if we were all equal? Then we should consider the different needs of, for instance, bilingual schools mentioned by Adam. The world of education does not function according to one model, applicable to everyone. The development model can also be understood in different ways. Maybe then it will be revealed that the concept of disability is empty, and can have a myriad of meanings, or none at all. This is where these oppressive strategies come from. This would also 
provide an opportunity to develop hybrid strategies that are less oppressive.

Agnieszka Woynarowska

I would just like to add, that in the concept my colleague referred to, disagreement is important. It is yet another way towards inclusive equality.

\section{Marta Sałkowska}

Well, Unfortunately our official time is up. The fact that we have space for such a discussion is exhilarating. However, there is a sense of unfulfillment due to time constraints. The Sociology of Disability Section should certainly organize more debates like this. Many inspiring ideas were presented, for instance, equality, inclusivity, biodiversity, neuro-diversity, intersectionality, the issues of the scope of the norm and the cultural approach. I think we will be thinking about these for a long time, and our discussion could've been even longer.

Thank you for your participation and commitment. This has been a very good debate.

Participants (in order of appearance)

Marta Sałkowska - an adjunct at the Institute of Sociology at Collegium Civitas, Warsaw. The main areas of research interest are disability studies and qualitative research methods. Co-worker of non-governmental organizations, author of reports and research studies on the situation of people with disabilities.

Elżbieta Zakrzewska-Manterys - a full professor at the Institute of Applied Social Sciences at the University of Warsaw. Her main research interests are methodology of the social sciences, sociological theory and sociology of disability. 
Magdalena Kocejko - a graduate of sociology and psychology at SWPS University of Social Sciences and Humanities, Warsaw. Consultant of many non-governmental organizations including those dealing with deafmutes.

Krzysztof Pezdek - a professor at the Department of Physiotherapy at the University of Physical Education in Wrocław. The author of many articles concerning theory of disability.

Rafał Dziurla - a PhD student at the Faculty of Psychology at the University of Warsaw and a Psychologist and Job Coach at the ECHO Foundation in Warsaw. President of the Board of the Polish Union of Supported Employment. $\mathrm{He}$ is the author and co-author of research and scientific publications in the field of rehabilitation psychology, quality of life and vocational rehabilitation of people with disabilities, as well as a cultural interpretation of disability.

Marta Abramczyk - deaf since early childhood. A graduate of psychology from the SWPS University of Social Sciences and Humanities, Warsaw. She defended her MA thesis on the differences in visual perception in deaf people. She is involved in society by Deaf people working in the Polish Association of the Deaf.

Maria Stojkow - an adjunct in the Department of Economic Sociology and Social Communication at AGH University of Science and Technology in Kraków. Her interest are disabilities and Muslim women.

Agnieszka Woynarowska - an adjunct in Faculty of Social Sciences (Division of Special Education) at the University of Gdansk. She defended her PhD thesis in Pedagogics titled Public discourse and individual experience of intellectual disability (2006).

Jolanta Rzeźnicka-Krupa - an adjunct in Faculty of Social Sciences (Division of Special Education) at the University of Gdansk. She defended her PhD in Pedagogics titled Discourse construction by children with intellectual disability. Pedagogical ethnographical study of pre-school group.

Milena Trojanowska - a PhD student at the University of Lodz, a sociologist. The main areas of research interest are sociology of disability and sociology of sexuality. On a daily basis, a participant in the lives of people with disabilities, an activist in non-governmental organizations.

Katarzyna Król - a PhD student at the Department of Sociology of Organization and Management at the University of Lodz. Her main scientific interests are disability, social activity, integration of disabled people, and social support. 
Adam Stoyanov - comes from a family where deafness is multigenerational. Polish sign language is his native language. He is involved in artistic and cultural activities as an actor and sign poet. He creates sign poetry that has no equivalent in phonic language. He is open, talks about his life hoping to increase awareness in society about Deaf people and their needs and facilities. 